\title{
Supplementation with the Extract of Schisandrae Fructus Pulp, Seed, or Their Combination Influences the Metabolism of Lipids and Glucose in Mice Fed with Normal and Hypercholesterolemic Diet
}

\author{
Xiao-Yan Wang, ${ }_{1}$ Zhi-Ling Yu, ${ }^{2}$ Si-Yuan Pan, ${ }^{1}$ Yi Zhang, ${ }^{1}$ Nan Sun, ${ }^{1}$ Pei-Li Zhu, \\ Zhan-Hong Jia, ${ }^{1}$ Shu-Feng Zhou, ${ }^{3}$ and Kam-Ming Ko ${ }^{4}$ \\ ${ }^{1}$ Department of Pharmacology, School of Chinese Materia Medica, Beijing University of Chinese Medicine, Beijing 100102, China \\ ${ }^{2}$ School of Chinese Medicine, Hong Kong Baptist University, Hong Kong \\ ${ }^{3}$ Department of Pharmaceutical Sciences, College of Pharmacy, University of South Florida, FL 33612, USA \\ ${ }^{4}$ Division of Life Science, Hong Kong University of Science \& Technology, Hong Kong
}

Correspondence should be addressed to Si-Yuan Pan; siyuan-pan@163.com

Received 16 February 2014; Revised 17 March 2014; Accepted 17 March 2014; Published 30 April 2014

Academic Editor: Gerhard Litscher

Copyright (C) 2014 Xiao-Yan Wang et al. This is an open access article distributed under the Creative Commons Attribution License, which permits unrestricted use, distribution, and reproduction in any medium, provided the original work is properly cited.

\begin{abstract}
Schisandrae Fructus (SF), which possesses five tastes: sweet (fruit skin), sour (pulp), bitter/pungent (seed core), and saltiness (all parts), can produce a wide spectrum of biological activities in the body. Here, we investigated the effects of the ethanolic extract of SF pulp, seed, or their combination (namely, EtSF-P, EtSF-S, or EtSF-P/S, resp.; collectively called EtSF) on the metabolism of lipids and glucose in normal diet- (ND-) and hypercholesterolemic diet- (HCLD-) fed mice. Supplementation with EtSF significantly reduced hepatic triglyceride and cholesterol levels by $18-47 \%$ in both ND- and HCLD-fed mice. EtSF supplementation reduced serum triglyceride levels (approximately 29\%), whereas EtSF-P and EtSF-S/P elevated serum cholesterol (up to 26 and $44 \%$, resp.) in HCLD-fed mice. Treatment with EtSF decreased hepatic glucose levels (by 9-44\%) in both ND- and HCLD-fed mice. Supplementation with EtSF-S or EtSF-S/P (at 1 and 3\%) increased biliary or fecal TC contents in HCLD-fed mice. However, supplementation with EtSF-S/P at 9\% reduced biliary TC levels in HCLD-fed mice. EtSF-P or EtSF-S/P supplementation reduced serum alanine aminotransferase activity in HCLD-fed mice. The findings suggested that supplementation with EtSF lowered lipid and glucose accumulation in the liver and increased fecal cholesterol contents in mice. Dietary supplementation with EtSF-P or EtSF-S/P attenuated liver damage in HCLD-fed mice.
\end{abstract}

\section{Introduction}

Hyperlipidemia (HLD) refers to increased levels of lipids in the blood, including cholesterol and triglyceride. It is well known that HLD, the leading cause of death and disability over the world, significantly increases the risk of cardiovascular diseases, nonalcoholic fatty liver disease (NAFLD), metabolic syndrome, stroke, or cerebrovascular accident [1-3]. NAFLD, which is the most common liver disease in western countries and with a clinical manifestation of steatosis and nonalcoholic steatohepatitis, is also recognized as a cause of cryptogenic cirrhosis and hepatocellular carcinoma [4]. A recent study has shown that the incidence of highly differentiated colorectal adenocarcinoma in NAFLD group is significantly higher than that in the control group [5]. In addition, NAFLD is associated with increased risk of hypertension [6], higher incidence of type 2 diabetes [7], and high levels of serum uric acid [8].

Since the incidences of HLD and NAFLD are increasing rapidly, it is of therapeutic interest to search for effective agents that can lower lipid contents in the blood and liver [9]. Although much effort has been put to develop drugs used for the prevention and treatment of HLD-related diseases, effective drugs for treating HLD, especially NAFLD, are 
yet to be discovered. In addition, synthetic lipid-lowering drugs have many potential adverse/side effects, such as muscle tenderness $[10,11]$, renal failure [12], and others, including headache, bowel upset, nausea, sleep disturbances, and hepatomegaly $[13,14]$. In recent years, people prefer to use natural remedy such as dietary supplement/functional food for the prevention and treatment of NAFLD and/or lipid disorders $[15,16]$.

Schisandrae Fructus (SF, Wu-Wei-Zi in Chinese) has been used for thousands of years as a "superior" drug in the practice of Chinese medicine in China. Previous studies have shown that SF and its related chemical components possess a wide spectrum of biological activities such as antioxidation, antitumor $[17,18]$, hepatoprotection against chemically and virally induced hepatic injury [19], antifatigue, immunostimulation, and antiaging [20]. A recent study has demonstrated that SF extract can prevent ethanolinduced fatty liver, possibly through activation of AMPK (AMP kinase) and peroxisome proliferator-activated receptor $\alpha(\operatorname{PPAR} \alpha)$ signaling pathway [21]. Gomisin N, a diastereomer of schisandrin B (Sch B, a major active ingredient of SF), inhibited DNA damage checkpoint signaling by stereospecifically interacting with ataxia telangiectasia and Rad3 -related (ATR) protein kinase [22]. Our previous studies have shown that SF extracts [23, 24], Sch B [25], bicycol [26], and bifendate [27] can reduce hepatic triglyceride (TG) and total cholesterol (TC) levels in hypercholesterolemic (HCL) mice. In the present study, we endeavored to compare the effects of ethanol extracts of SF pulp, seed, or a mixture of pulp/seed on serum and hepatic lipid/glucose (GLU) levels, as well as liver function in mice under the normal and HCL conditions. Fenofibrate (FF) was used as a positive control for comparison.

\section{Materials and Methods}

2.1. Herbal Material and Extraction Procedure. SF, which is the fruit of Schisandra chinensis (Turcz.) Baillon (Bei-WuWei-Zi in Chinese), was purchased from the Anguo Chinese herbs market in Hebei province, China, and authenticated by Professor Chun-Sheng Liu at the Beijing University of Chinese Medicine. The fruit pulp and seed were manually separated and then dried at room temperature. The weight of pulp and seed was 63 and $37 \%$ of total weight, respectively. For the preparation of SF extracts, SF pulp, seed, or both were crushed into small pieces using an industrial grinder and extracted twice (first, $1.5 \mathrm{~h}$; second, $2 \mathrm{~h}$ ) with 5 volumes of $80 \%$ (v/v, in $\mathrm{H}_{2} \mathrm{O}$ ) ethanol under reflux after soaking for half an hour. The pooled extract was filtered by filter paper and concentrated by rotary evaporation to obtain the SF seed ethanolic extract (EtSF-S), SF pulp ethanolic extract (EtSF-P), and their combination extracts (EtSF-S/P). The extracts were stored at $4^{\circ} \mathrm{C}$ until use.

2.2. Chemicals and Regents. Cholesterol (certificate number 20120614) and bile salt (certificate number 20121210) were purchased from Sinopharm Chemical Reagent Co., Ltd. (Beijing, China). FF (certificate number 18246) was obtained from Beijing Yongkang Medical Ltd. (Beijing, China). Assay kits for TC, TG, and GLU were bought from Zhongsheng Beikong Biotechnology and Science Inc. (Beijing, China). Assay kits for high-density lipoprotein cholesterol (HDL), low-density lipoprotein cholesterol (LDL), and alanine aminotransferase (ALT) were purchased from Beijing Leadman Biochemistry Co., Ltd. (Beijing, China).

2.3. Animal and Treatment. All experimental procedures were approved by the University Committee on Research Practice at Beijing University of Chinese Medicine. Male ICR mice (grade II, certificate number SCXK (jing) 2012-0001), weighing 18-20 g, were supplied by Vital River Lab Animal Co. Ltd. (Beijing, China). All animals were maintained on a $12 \mathrm{~h}$ (light on $700-1900 \mathrm{~h}$ ) light-dark cycle at $20-21^{\circ} \mathrm{C}$, with a relative humidity of $50-55 \%$. They were allowed for free access to water and food.

\subsection{Experimental Design}

2.4.1. Design 1. In this study, the effects of dietary supplementation with SF extracts or FF on lipids, GLU, and liver were investigated in normal mice. Animals were divided into four groups of 10 animals in each: (1) mice fed with normal diet (ND); (2) and (3) mice fed with diet supplemented with $1 \%$ and $9 \%$ SF extracts (w/w), respectively; (4) mice fed with diet supplemented with $0.1 \%$ FF. After 10 days, mice were sacrificed under light ether anesthesia. Blood, collected from the orbital vein, and liver tissue samples were obtained and subjected to biochemical analysis.

2.4.2. Design 2. This study was designed to investigate the effects of SF extracts on serum and hepatic parameters in mice fed with HCL diet (HCLD) containing cholesterol/bill salt $(1 / 0.3 \%, w / w)$. Mice were randomly divided into six groups (10 in each group): (1) mice fed with ND; (2) mice fed with HCLD; (3), (4), and (5) mice fed with HCLD supplemented with 1, 3, and 9\% EtSF-S, EtSF-P, or EtSF$\mathrm{S} / \mathrm{P}$, respectively; (6) mice fed with HCLD supplemented with $0.1 \%$ FF. Ten days later, animals were sacrificed and blood/liver tissue samples were collected for biochemical analysis. Figure 1 shows the design of the present study.

2.5. Serum and Hepatic Biochemical Analysis. Serum samples were prepared by centrifuging the clotted blood for $8 \mathrm{~min}$ at $2000 \times \mathrm{g}$ and stored at $-20^{\circ} \mathrm{C}$ until used for biochemical analysis. Liver tissue samples were homogenized in 9 volumes of $0.9 \%(\mathrm{w} / \mathrm{v}) \mathrm{NaCl}$ solution by two $10 \mathrm{~s}$ bursts of a tissue disintegrator at $13,500 \mathrm{rpm}$ and then centrifuged at $2000 \times \mathrm{g}$ for $15 \mathrm{~min}$ to obtain the supernatants. Ten $\mu \mathrm{L}$ of serum and $40 \mu \mathrm{L}$ of the hepatic supernatant were used to determine the TG and TC levels with GPO-PAP and COD-PAP methods, respectively. Ten $\mu \mathrm{L}$ serum and $5 \mu \mathrm{L}$ hepatic supernatant were used to determine the GLU levels with GOD-POD method. Serum HDL and LDL levels, as well as ALT activity, were determined using automatic biochemistry analyzer (Beckman Coulter Synchron CX4 PRO.Brea, CA, USA). 


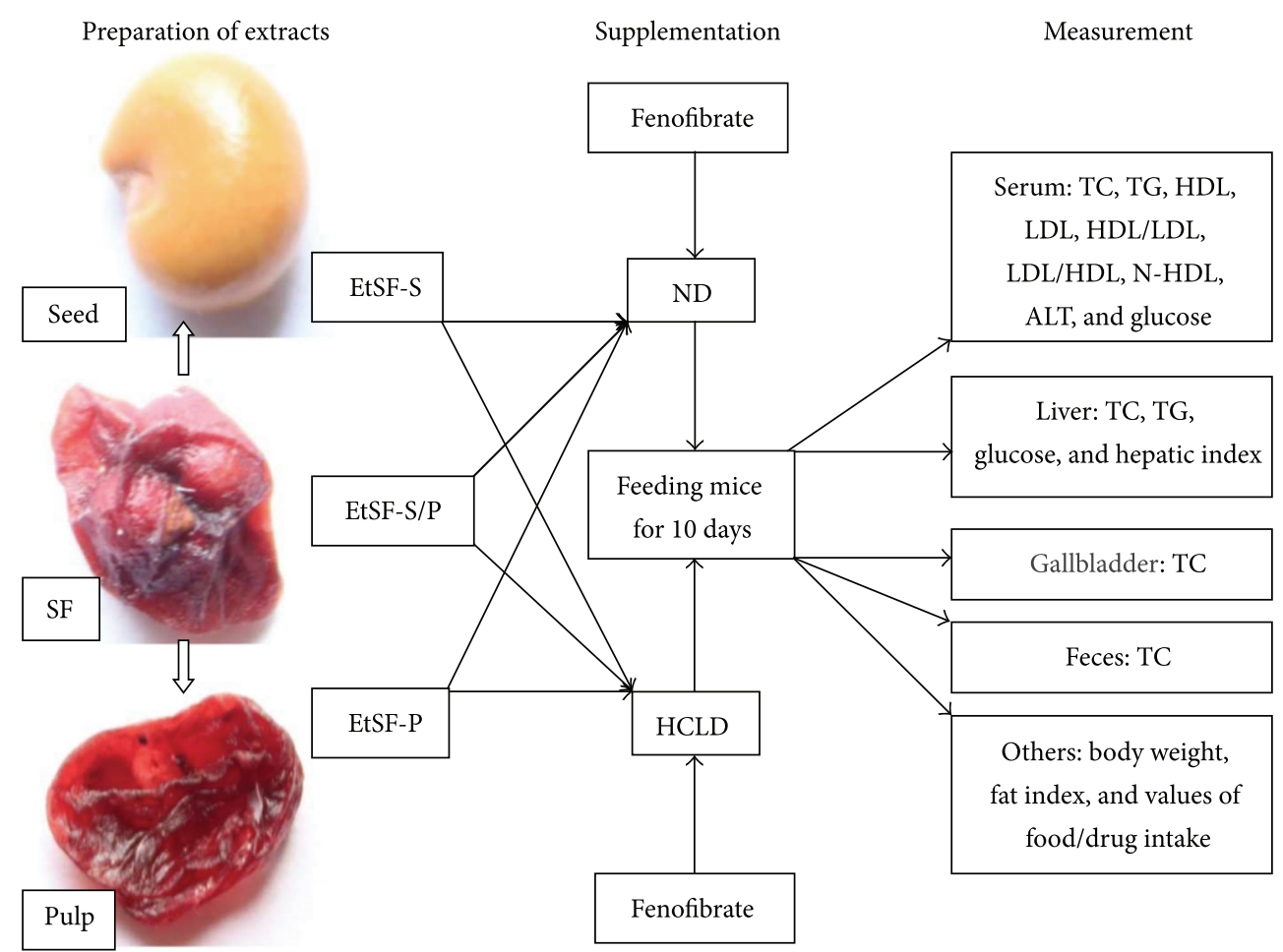

FIgURE 1: The design of the current study. SF: Schisandra Fructus; EtSF-S: ethanolic extract of SF seed; EtSF-P: ethanolic extract of SF pulp; EtSF-S/P: ethanolic extract of SF seed/pulp; TC: total cholesterol; TG: triglyceride; LDL: low-density lipoprotein; HDL: high-density lipoprotein; N-HDL: non-HDL; ALT: alanine aminotransferase; HCLD: hypercholesterolemic diet; ND: normal diet.

2.6. Measurement of Biliary and Fecal TC Contents. Mouse gallbladder was removed from the liver and soaked in $1 \mathrm{~mL}$ TC reagent for $16 \mathrm{~h}$. Then TC concentrations ( $\mu \mathrm{mol} /$ gallbladder) were measured using the method described above. For the determination of TC contents in feces, mouse feces were collected and dried at room temperature. Dried feces (approximately $30 \mathrm{mg}$ ) were extracted with $0.5 \mathrm{~mL}$ chloroform-methanol $(1: 1, \mathrm{v} / \mathrm{v})$ mixture for $12 \mathrm{~h}$ and then centrifuged at $2000 \times \mathrm{g}$ for $5 \mathrm{~min}$ to obtain the supernatants. Thirty $\mu \mathrm{L}$ fecal supernatants were used to measure the TC levels ( $\mu \mathrm{mol} / \mathrm{g}$ feces) using assay kit.

2.7. Measurement of Hepatic Index. Body and liver weights were measured. Hepatic index was estimated from the ratio of total liver weight to body weight (liver weight/body weight $x$ 100).

2.8. Statistical Analysis. Values given are means \pm SEM. Data were analyzed by one-way ANOVA using SPSS statistical analysis program and then differences among means were analyzed by Dunnett's multiple comparisons test or post hoc analysis. $P<0.05$ was considered significant.

\section{Results}

3.1. Effects of EtSF Supplementation on Serum Lipid Profiles. As shown in Table 1, daily supplementation with EtSF (i.e., EtSF-S, EtSF-P, and EtSF-S/P) did not affect serum TC, TG, and HDL levels in mice fed with ND. However, both EtSF$\mathrm{P}$ and EtSF-S/P supplementation markedly increased serum HDL and LDL levels (up to $15-47 \%$ and $14-73 \%$, resp.) in ND- and HCLD-fed mice. All 3 tested EtSF extracts decreased serum TG levels (up to 25\%) in HCLD-fed mice, but EtSF-P and EtSF-S/P markedly increased serum TC levels (approximately 26 and 44\%, resp.) in mice fed with HCLD. Feeding mice with HCLD markedly increased serum TC, LDL, and N-HDL levels, as well as LDL/HDL ratio. HCLD decreased serum TG level (up to 60\%) and HDL/LDL ratio, when compared with ND-fed mice. EtSF-S supplementation did not affect serum HDL/LDL and LDL/HDL ratios, but decreased N-HDL level in ND-fed mice. EtSF-P and EtSF$\mathrm{S} / \mathrm{P}$ supplementation decreased serum HDL/LDL ratio and increased LDL/HDL ratio and N-HDL levels in both NDfed and HCBD-fed mice. FF supplementation reduced serum TC (32\%), TG (52\%), HDL (34\%), or HDL/LDL ratio but increased LDL/HDL ratio, in normal mice. Serum TC, TG, LDL, and N-HDL levels were reduced by $29,38,66$, and $69 \%$, respectively, in mice fed with FF-supplemented HCLD diet, when compared with those fed with HCLD only. Moreover, FF elevated serum HDL/LDL ratio but decreased LDL/HDL ratio in HCLD-fed mice.

3.2. Effects of EtSF Supplementation on Hepatic Lipid/Glucose Levels. Supplementation with EtSF-S, EtSF-P, or EtSF-S/P decreased hepatic TC and TG contents (up to 47\%) in ND-fed mice. Feeding mice with HCLD markedly increased hepatic TC and TG contents (up to 447 and 402\%, resp.), when 
TABLE 1: Effects of EtSF supplementation on serum lipid profiles in normal and HCL mice.

\begin{tabular}{|c|c|c|c|c|c|c|c|c|}
\hline Groups & $\begin{array}{c}\text { Drug } \\
(\%)\end{array}$ & $\mathrm{TC}(\mathrm{mmol} / \mathrm{L})$ & $\mathrm{TG}(\mathrm{mmol} / \mathrm{L})$ & $\begin{array}{c}\text { HDL } \\
(\mathrm{mmol} / \mathrm{L})\end{array}$ & $\mathrm{LDL}(\mathrm{mmol} / \mathrm{L})$ & HDL/LDL & LDL/HDL & $\begin{array}{c}\text { N-HDL } \\
(\mathrm{mmol} / \mathrm{L})\end{array}$ \\
\hline \multicolumn{9}{|l|}{ ND-fed mice } \\
\hline ND & - & $3.39 \pm 0.10$ & $1.24 \pm 0.06$ & $3.57 \pm 0.12$ & $0.44 \pm 0.02$ & $8.18 \pm 0.35$ & $0.13 \pm 0.01$ & $0.65 \pm 0.02$ \\
\hline \multirow{2}{*}{ ND/EtSF-S } & 1 & $3.37 \pm 0.14$ & $1.29 \pm 0.08$ & $3.66 \pm 0.19$ & $0.45 \pm 0.02$ & $8.27 \pm 0.57$ & $0.13 \pm 0.01$ & $0.53 \pm 0.05^{*}$ \\
\hline & 9 & $3.25 \pm 0.12$ & $1.05 \pm 0.15$ & $3.58 \pm 0.14$ & $0.45 \pm 0.03$ & $8.07 \pm 0.43$ & $0.13 \pm 0.01$ & $0.46 \pm 0.05^{* *}$ \\
\hline $\mathrm{ND} / \mathrm{FF}$ & 0.1 & $2.32 \pm 0.10^{* *}$ & $0.60 \pm 0.03^{* *}$ & $2.36 \pm 0.14^{* *}$ & $0.40 \pm 0.03$ & $6.12 \pm 0.38^{* *}$ & $0.17 \pm 0.01^{* *}$ & $0.68 \pm 0.03$ \\
\hline ND & - & $4.23 \pm 0.25$ & $1.81 \pm 0.05$ & $3.64 \pm 0.18$ & $0.47 \pm 0.03$ & $7.90 \pm 0.38$ & $0.13 \pm 0.01$ & $0.71 \pm 0.12$ \\
\hline \multirow{2}{*}{ ND/EtSF-P } & 1 & $4.28 \pm 0.16$ & $1.81 \pm 0.06$ & $3.66 \pm 0.17$ & $0.49 \pm 0.03$ & $7.62 \pm 0.42$ & $0.14 \pm 0.01$ & $0.71 \pm 0.09$ \\
\hline & 9 & $4.44 \pm 0.19$ & $1.78 \pm 0.17$ & $3.72 \pm 0.14$ & $0.62 \pm 0.05^{*}$ & $6.25 \pm 0.57^{*}$ & $0.17 \pm 0.02^{*}$ & $0.83 \pm 0.09$ \\
\hline ND & - & $4.28 \pm 0.14$ & $1.82 \pm 0.18$ & $3.67 \pm 0.16$ & $0.59 \pm 0.04$ & $6.44 \pm 0.42$ & $0.16 \pm 0.01$ & $0.61 \pm 0.04$ \\
\hline \multirow{2}{*}{ ND/EtSF-S/P } & 1 & $4.31 \pm 0.17$ & $1.93 \pm 0.19$ & $3.52 \pm 0.14$ & $0.78 \pm 0.04^{* *}$ & $4.62 \pm 0.20^{* *}$ & $0.22 \pm 0.01^{* *}$ & $0.78 \pm 0.06^{*}$ \\
\hline & 9 & $4.67 \pm 0.15$ & $2.09 \pm 0.11$ & $4.09 \pm 0.18$ & $0.74 \pm 0.03^{* *}$ & $5.52 \pm 0.12^{*}$ & $0.18 \pm 0.004$ & $0.58 \pm 0.05$ \\
\hline \multicolumn{9}{|l|}{ HCLD-fed mice } \\
\hline ND & - & $4.15 \pm 0.16$ & $1.79 \pm 0.10$ & $3.70 \pm 0.19$ & $0.56 \pm 0.04$ & $6.71 \pm 0.33$ & $0.15 \pm 0.01$ & $0.45 \pm 0.05$ \\
\hline HCLD & - & $5.59 \pm 0.27^{* *}$ & $1.24 \pm 0.06^{* *}$ & $3.60 \pm 0.17$ & $2.21 \pm 0.12^{* *}$ & $1.64 \pm 0.06^{* *}$ & $0.62 \pm 0.02^{* *}$ & $1.99 \pm 0.15^{* *}$ \\
\hline \multirow{3}{*}{ HCLD/EtSF-S } & 1 & $5.74 \pm 0.23$ & $0.97 \pm 0.05^{\dagger \dagger}$ & $3.57 \pm 0.09$ & $2.38 \pm 0.13$ & $1.52 \pm 0.06$ & $0.67 \pm 0.03$ & $2.18 \pm 0.17$ \\
\hline & 3 & $5.68 \pm 0.14$ & $1.08 \pm 0.05$ & $3.70 \pm 0.08$ & $2.23 \pm 0.08$ & $1.67 \pm 0.05$ & $0.60 \pm 0.02$ & $1.98 \pm 0.10$ \\
\hline & 9 & $5.68 \pm 0.16$ & $0.96 \pm 0.07^{\dagger \dagger}$ & $3.68 \pm 0.09$ & $2.31 \pm 0.13$ & $1.63 \pm 0.08$ & $0.63 \pm 0.03$ & $2.00 \pm 0.12$ \\
\hline $\mathrm{HCLD} / \mathrm{FF}$ & 0.1 & $3.95 \pm 0.22^{\dagger \dagger}$ & $0.77 \pm 0.04^{\dagger \dagger}$ & $3.34 \pm 0.23$ & $0.76 \pm 0.07^{\dagger \dagger}$ & $4.62 \pm 0.31^{\dagger \dagger}$ & $0.23 \pm 0.02^{\dagger \dagger}$ & $0.61 \pm 0.06^{\dagger \dagger}$ \\
\hline $\mathrm{ND}$ & - & $4.23 \pm 0.25$ & $1.81 \pm 0.05$ & $3.64 \pm 0.18$ & $0.47 \pm 0.03$ & $7.90 \pm 0.38$ & $0.13 \pm 0.01$ & $0.71 \pm 0.12$ \\
\hline HCLD & - & $5.06 \pm 0.23^{*}$ & $1.01 \pm 0.06^{* *}$ & $3.22 \pm 0.11$ & $1.55 \pm 0.05^{* *}$ & $2.05 \pm 0.11^{* *}$ & $0.50 \pm 0.02^{* *}$ & $1.95 \pm 0.15^{* *}$ \\
\hline \multirow{3}{*}{ HCLD/EtSF-P } & 1 & $4.98 \pm 0.15$ & $1.04 \pm 0.08$ & $3.23 \pm 0.09$ & $1.61 \pm 0.07$ & $2.03 \pm 0.08$ & $0.50 \pm 0.02$ & $1.75 \pm 0.13$ \\
\hline & 3 & $5.61 \pm 0.20$ & $0.92 \pm 0.08$ & $3.60 \pm 0.14$ & $1.74 \pm 0.09$ & $2.03 \pm 0.09$ & $0.50 \pm 0.02$ & $2.01 \pm 0.10$ \\
\hline & 9 & $6.38 \pm 0.20^{\dagger \dagger}$ & $0.76 \pm 0.06^{\dagger \dagger}$ & $3.70 \pm 0.14^{\dagger}$ & $2.28 \pm 0.09^{\dagger \dagger}$ & $1.59 \pm 0.07^{\dagger \dagger}$ & $0.64 \pm 0.03^{\dagger \dagger}$ & $2.69 \pm 0.13^{\dagger \dagger}$ \\
\hline ND & - & $4.28 \pm 0.14$ & $1.82 \pm 0.18$ & $3.67 \pm 0.16$ & $0.59 \pm 0.04$ & $6.44 \pm 0.42$ & $0.16 \pm 0.01$ & $0.61 \pm 0.04$ \\
\hline HCLD & - & $5.10 \pm 0.18^{* *}$ & $0.73 \pm 0.06^{* *}$ & $3.74 \pm 0.13$ & $1.97 \pm 0.11^{* *}$ & $1.95 \pm 0.12^{* *}$ & $0.53 \pm 0.04^{* *}$ & $1.35 \pm 0.13^{* *}$ \\
\hline \multirow{3}{*}{ HCLD/EtSF-S/P } & 1 & $6.40 \pm 0.16^{\dagger \dagger}$ & $0.69 \pm 0.07$ & $4.26 \pm 0.09^{\dagger \dagger}$ & $2.88 \pm 0.11^{\dagger \dagger}$ & $1.50 \pm 0.07^{\dagger \dagger}$ & $0.68 \pm 0.03^{\dagger \dagger}$ & $2.14 \pm 0.12^{\dagger \dagger}$ \\
\hline & 3 & $6.34 \pm 0.31^{\dagger \dagger}$ & $0.57 \pm 0.04^{\dagger}$ & $4.01 \pm 0.19$ & $2.80 \pm 0.16^{\dagger \dagger}$ & $1.45 \pm 0.07^{\dagger \dagger}$ & $0.70 \pm 0.03^{\dagger \dagger}$ & $2.33 \pm 0.18^{\dagger \dagger}$ \\
\hline & 9 & $7.32 \pm 0.23^{\dagger \dagger}$ & $0.60 \pm 0.05$ & $4.38 \pm 0.12^{\dagger \dagger}$ & $3.41 \pm 0.16^{\dagger \dagger}$ & $1.30 \pm 0.06^{\dagger \dagger}$ & $0.78 \pm 0.04^{\dagger \dagger}$ & $2.94 \pm 0.20^{\dagger \dagger}$ \\
\hline
\end{tabular}

Mice were fed with normal diet (ND) or hypercholesterolemic diet (HCLD) without and with the ethanolic extract of Schisandrae Fructus (SF) pulp, seed, or their combination (namely, EtSF-P, EtSF-S, and EtSF-P/S, resp.) and fenofibrate (FF) at the indicated doses (\%, w/w), which was estimated on the basis of crude herbal material, for 10 days. Then serum total cholesterol (TC), triglyceride (TG), high-density lipoprotein (HDL), low-density lipoprotein (LDL), and non-HDL (N-HDL) levels, as well as HDL/LDL and LDL/HDL ratios, were measured. HCLD was constituted of $1 \%$ cholesterol and $0.3 \%$ bile salt (w/w). Values given are the means $\pm \mathrm{SEM}$, with $n=10 .{ }^{*} P<0.05,{ }^{* *} P<0.01$ versus ND; ${ }^{\dagger} P<0.05,{ }^{\dagger \dagger} P<0.01$ versus HCLD. Statistical significant differences were determined using a one-way ANOVA followed by Dunnett's multiple comparisons test or post hoc analysis.

compared with those of mice fed with ND. Supplementation with EtSF-S, EtSF-P, or EtSF-S/P reduced the hepatic TC and TG contents by $18-37 \%$ and $23-30 \%$, respectively, in HCL mice. FF supplementation lowered hepatic TC/TG contents by $64 / 49$ and $81 / 55 \%$ in both normal and HCL mice, respectively (Figures 2(a) and 2(b)). Dietary supplementation with 3 tested SF extracts and FF reduced hepatic GLU contents by $10 / 44 \%$ and $58 / 44 \%$ in ND-/HCLD-fed mice, respectively (Figure $2(\mathrm{c})$ ).

3.3. Effects of EtSF Supplementation on Biliary and Fecal Cholesterol Contents. EtSF-S and 1\% EtSF-S/P, but not EtSF$\mathrm{P}$, supplementation increased biliary TC concentrations in HCLD-fed mice (up to 136 and 60\%, resp.). However, supplementation with $9 \%$ EtSF-S/P reduced biliary TC by $30 \%$ in
HCL mice (Figure 3(a)). Feeding mice with 9\% EtSF-P and EtSF-S/P elevated the fecal cholesterol excretion (by 21 and $62 \%$, resp.) (Figure 3(b)).

\subsection{Effects of EtSF Supplementation on Hepatic Index and} Function. Feeding mice with EtSF-S/P or HCLD increased hepatic index by 10 or $18 \%$, respectively, when compared with control ND group. FF increased hepatic index by 95 and $79 \%$, respectively, in normal and HCL mice, respectively (Figure 4(a)). EtSF did not alter the serum ALT activity in normal mice, but EtSF-P and EtSF-S/P lowered the ALT activity (33 and $24 \%$ decrease, resp.) in HCL mice. FF supplementation significantly elevated serum ALT activity by 209 and $650 \%$, respectively, in ND- and HCLD-fed mice (Figure 4(b)). 


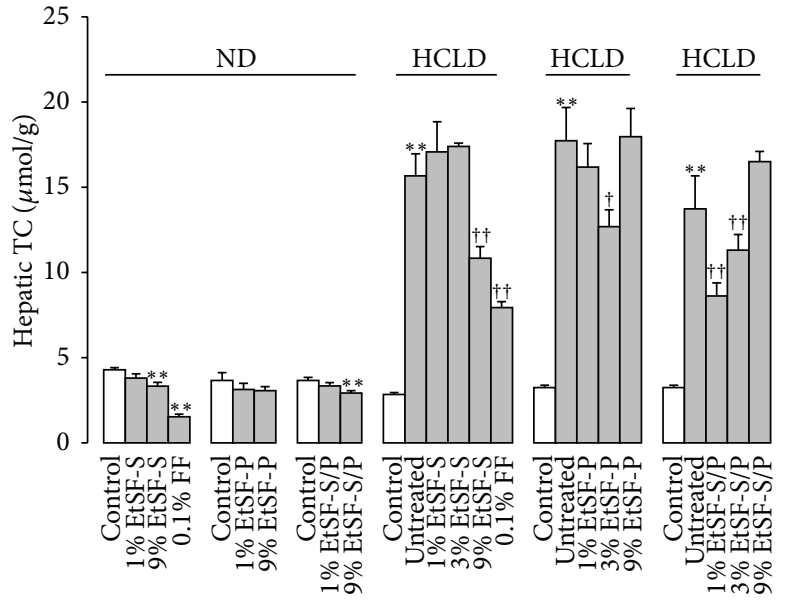

(a)

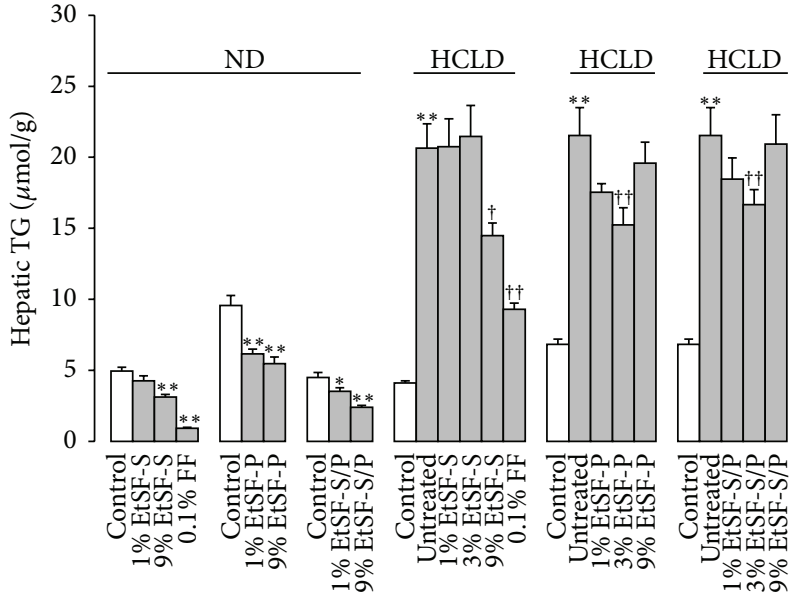

(b)

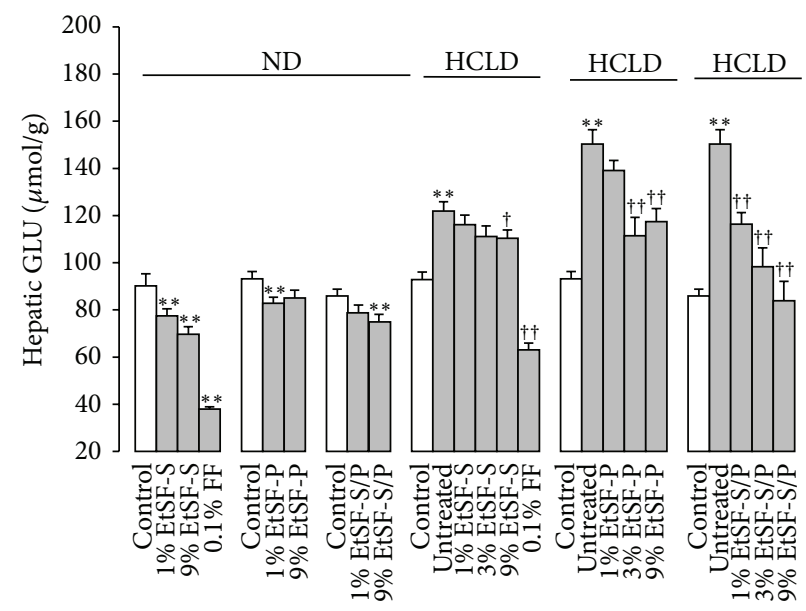

(c)

FIGURE 2: Effects of EtSF supplementation on hepatic lipid/glucose contents in normal and HCL mice. Experimental details were described in Table 1. Mice were fed with ND and HCLD without or with EtSF or FF supplementation, as indicated in the figure. Ten days later, hepatic TC (a), TG (b), and glucose (c) contents were measured. Values given are the means \pm SEM, with $n=10 .{ }^{*} P<0.05$, ${ }^{* *} P<0.01$ versus mice fed with ND and ${ }^{\dagger} P<0.05,{ }^{\dagger \dagger} P<0.01$ versus mice fed with HCLD alone. Statistically significant differences were determined using a one-way ANOVA followed by Dunnett's multiple comparisons test or post hoc analysis.

3.5. Effects of EtSF Supplementation on Body Weight and Food/Drug Intake. EtSF-P supplementation decreased the body weight (up to $6 \% ; P<0.05$ ) in ND-, but not HCLD-, fed mice. However, no detectable changes in body weight between EtSF-S/EtSF-S/P supplemented and unsupplemented mice fed with ND and HCLD were observed. In addition, weight loss was observed in FF-supplemented mice with ND (by $8 \%$ ) and HCLD (by 16\%). Daily intake of EtSF-S, EtSF-P, or EtSF-S/P was estimated to be $1.47-1.68 \mathrm{~g} / \mathrm{kg}$ (based on crude herb equivalent) at $1 \%$ supplementation, $4.23-5.47 \mathrm{~g} / \mathrm{kg}$ at $3 \%$ supplementation, and $12.72-15.43 \mathrm{~g} / \mathrm{kg}$, at $9 \%$ supplementation. The human equivalent dose of $1 \%$ EtSF is estimated to be $0.15-0.17 \mathrm{~g}$ crude herb $/ \mathrm{kg}$. The daily intake of FF was estimated to be 0.15 and $0.13 \mathrm{~g} / \mathrm{kg}$ in normal and HCL mice, respectively (Table 2).

\section{Discussion}

While genetic inheritance may contribute to the development of HLD and its related NAFLD in some patients, the main pathological causes are related to the lack of exercise and diet with high levels of saturated fats and carbohydrates [3]. In the present study, mice fed with a diet containing cholesterol and bile salt for 10 days exhibited elevations in serum TC, LDL levels, and ALT activity, as well as hepatic TC, TG, and GLU levels, which were associated with hepatomegaly and liver injury. Biliary and fecal TC concentrations were also increased in mice fed with HCLD. It was observed that feeding mice with HCLD for ten days was able to increase serum LDL level but causes no detectable change in serum HDL. The findings indicated that HLD and/or NAFLD in humans were successfully mimicked by a mouse model of feeding 


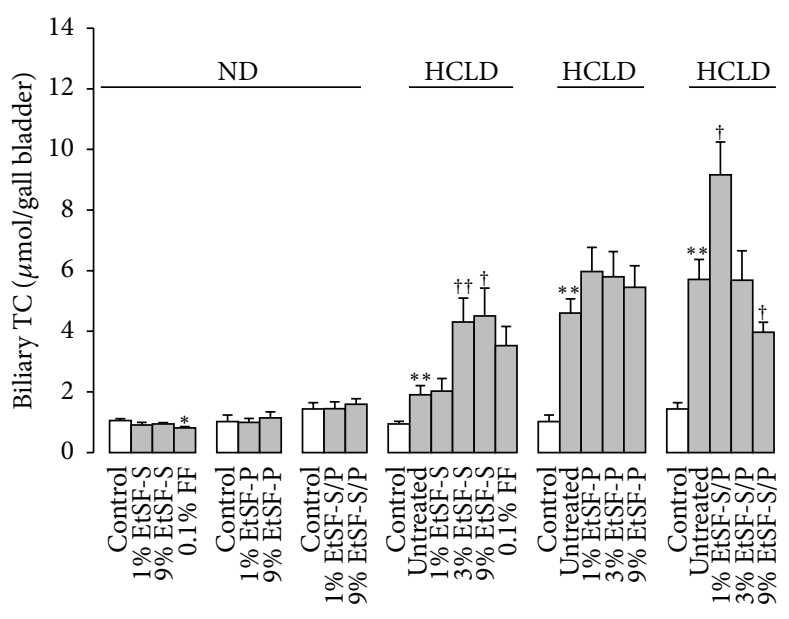

(a)

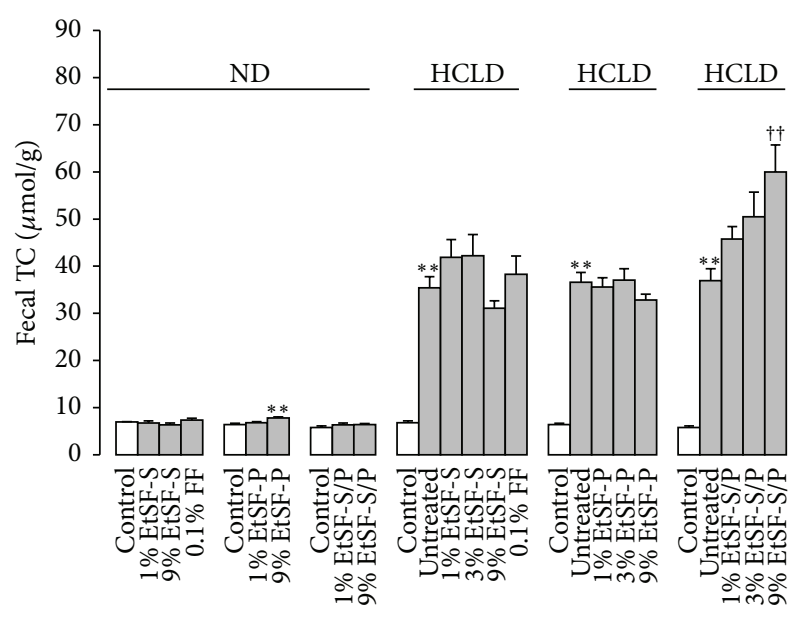

(b)

FIGURE 3: Effects of EtSF supplementation on biliary and fecal cholesterol contents in normal and HCL mice. Experimental details were described in Table 1. Mice were fed with ND and HCLD without or with EtSF or FF supplementation, as indicated in the figure. Ten days later, biliary (a) and fecal (b) TC contents were measured. Values given are the means $\pm \mathrm{SEM}$, with $n=10 .{ }^{*} P<0.05$, ${ }^{* *} P<0.01$ versus mice fed with ND and ${ }^{\dagger} P<0.05,{ }^{\dagger \dagger} P<0.01$ versus mice fed with HCLD alone. Statistically significant differences were determined using a one-way ANOVA followed by Dunnett's multiple comparisons test or post hoc analysis.

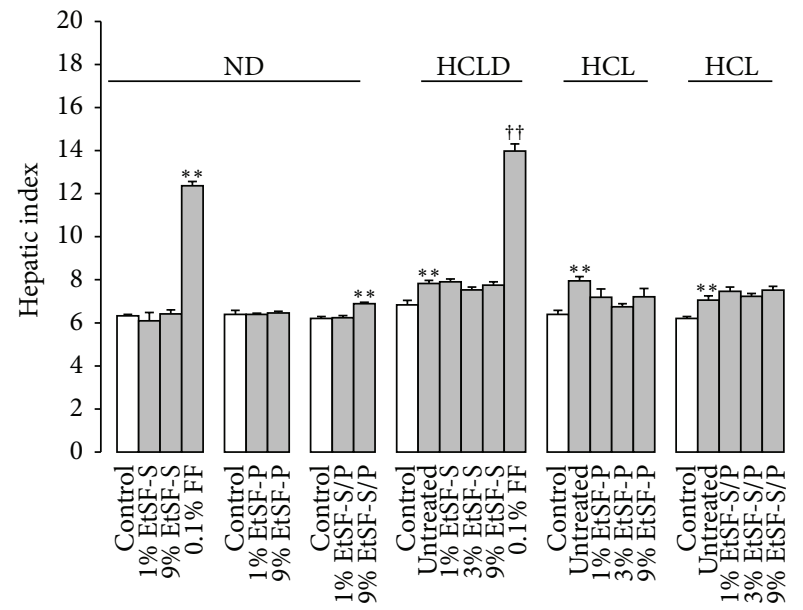

(a)

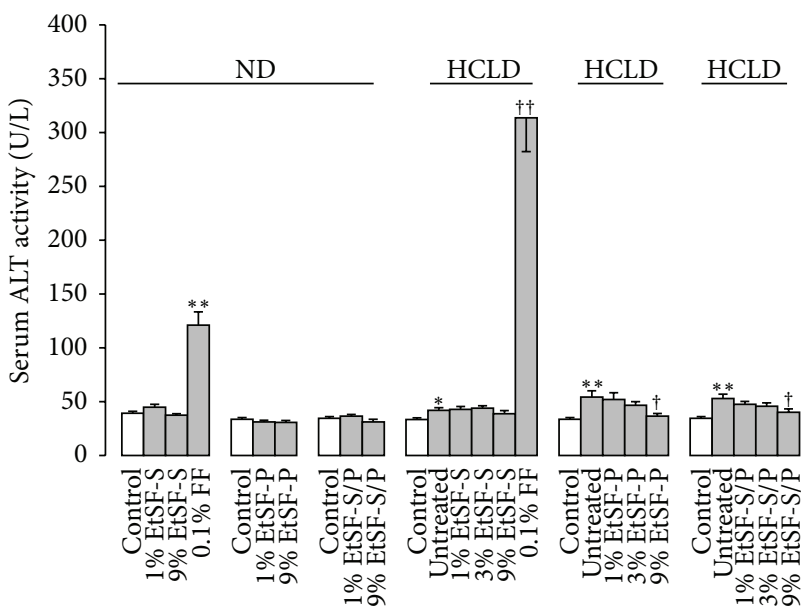

(b)

FIGURE 4: Effects of EtSF supplementation on hepatic index and function in normal and HCL mice. Experimental details were described in Table 1. Mice were fed with ND and HCLD without or with EtSF or FF supplementation, as indicated in the figure. Ten days later, hepatic index (a) and serum alanine aminotransferase (ALT) activity (b) were measured. Values given are the means \pm SEM, with $n=10 .{ }^{*} P<$ $0.05,{ }^{* *} P<0.01$ versus mice fed with ND and ${ }^{\dagger} P<0.05,{ }^{\dagger \dagger} P<0.01$ versus mice fed with HCLD alone. Statistically significant differences were determined using a one-way ANOVA followed by Dunnett's multiple comparisons test or post hoc analysis.

HCLD. Nevertheless, the low levels of serum TG, as observed in the mouse model, may be related to the short period (10 days) of modeling, HCLD composition, and/or interspecies differences $[28,29]$. In clinical situation, however, serum TG level is often not a concomitant parameter in HCL; it may increase or remain unchanged but never be lower than the normal range.

Given that N-HDL, HDL/LDL ratio, and LDL/HDL ratio are clinical parameters for assessing the risk of cardiovascular diseases, NAFLD, and metabolic syndrome in humans [3032], these parameters were also adopted for evaluating the effectiveness of the tested EtSF extracts in mice fed with HCLD. Feeding mice with HCLD increased serum LDL/HDL ratio and $\mathrm{N}-\mathrm{HDL}$ levels but decreased the HDL/LDL ratio, which are consistent with the clinical manifestation of HLD [33-35]. FF supplementation increased HDL/LDL ratio and decreased N-HDL levels and LDL/HDL ratio in HCL mice. On the other hand, the supplementation with EtSF-P and EtSF-S/P decreased HDL/LDL ratio and elevated N-HDL levels and LDL/HDL ratio. While EtSF-P and EtSF-S/P lowered serum TG and enhanced serum HDL, both EtSF extracts increased serum TC and N-HDL levels and LDL/HDL ratio, 
TABLE 2: Effects of EtSF supplementation on body weight and food/drug intake in normal and HCL mice.

\begin{tabular}{|c|c|c|c|c|c|}
\hline Groups & $\begin{array}{c}\text { Drug } \\
\text { concentration } \\
(\%, \mathrm{w} / \mathrm{w})\end{array}$ & $\begin{array}{l}\text { Body weight }(\mathrm{g}) \text { in } \\
\text { D } 1\end{array}$ & $\begin{array}{l}\text { Body weight }(\mathrm{g}) \text { in } \\
\text { D } 10\end{array}$ & $\begin{array}{l}\text { Food intake } \\
(\mathrm{g} / \mathrm{kg} / \text { day })\end{array}$ & $\begin{array}{l}\text { Drug intake } \\
(\mathrm{g} / \mathrm{kg} / \text { day })\end{array}$ \\
\hline \multicolumn{6}{|l|}{ ND-fed mice } \\
\hline ND & - & $18.55 \pm 0.09$ & $28.70 \pm 0.53$ & 148.54 & - \\
\hline \multirow{2}{*}{ ND/EtSF-S } & 1 & $18.58 \pm 0.09$ & $28.10 \pm 0.45$ & 147.80 & 1.48 \\
\hline & 9 & $18.56 \pm 0.09$ & $28.24 \pm 0.53$ & 151.48 & 13.63 \\
\hline $\mathrm{ND} / \mathrm{FF}$ & 0.1 & $18.52 \pm 0.11$ & $26.36 \pm 0.65^{*}$ & 145.27 & 0.15 \\
\hline ND & - & $18.14 \pm 0.18$ & $28.02 \pm 0.45$ & 158.60 & - \\
\hline \multirow{2}{*}{ ND/EtSF-P } & 1 & $18.08 \pm 0.18$ & $26.55 \pm 0.52^{*}$ & 147.39 & 1.47 \\
\hline & 9 & $18.03 \pm 0.19$ & $26.38 \pm 0.41^{*}$ & 165.29 & 14.88 \\
\hline ND & & $18.52 \pm 0.10$ & $28.02 \pm 0.51$ & 154.29 & - \\
\hline \multirow{2}{*}{ ND/EtSF-S/P } & 1 & $18.48 \pm 0.11$ & $27.87 \pm 0.50$ & 146.88 & 1.47 \\
\hline & 9 & $18.55 \pm 0.11$ & $28.42 \pm 0.45$ & 145.30 & 13.08 \\
\hline \multicolumn{6}{|l|}{ HCLD-fed mice } \\
\hline ND & - & $18.60 \pm 0.16$ & $28.48 \pm 0.50$ & 156.21 & - \\
\hline HCLD & - & $18.68 \pm 0.18$ & $28.48 \pm 0.49$ & 143.35 & - \\
\hline \multirow{3}{*}{ HCLD/EtSF-S } & 1 & $18.55 \pm 0.17$ & $29.49 \pm 0.53$ & 145.75 & 1.46 \\
\hline & 3 & $18.65 \pm 0.16$ & $28.48 \pm 0.72$ & 141.09 & 4.23 \\
\hline & 9 & $18.62 \pm 0.17$ & $28.07 \pm 0.47$ & 141.31 & 12.72 \\
\hline $\mathrm{HCLD} / \mathrm{FF}$ & 0.1 & $18.67 \pm 0.19$ & $23.81 \pm 0.62^{\dagger \dagger}$ & 132.00 & 0.13 \\
\hline ND & - & $18.14 \pm 0.18$ & $28.02 \pm 0.45$ & 158.60 & - \\
\hline HCLD & - & $18.63 \pm 0.22$ & $27.74 \pm 0.59$ & 159.60 & - \\
\hline \multirow{3}{*}{ HCLD/EtSF-P } & 1 & $18.92 \pm 0.34$ & $28.17 \pm 0.62$ & 164.80 & 1.65 \\
\hline & 3 & $18.45 \pm 0.25$ & $28.55 \pm 0.79$ & 182.16 & 5.47 \\
\hline & 9 & $18.41 \pm 0.29$ & $27.06 \pm 0.45$ & 171.46 & 15.43 \\
\hline ND & - & $18.52 \pm 0.10$ & $28.02 \pm 0.51$ & 154.29 & - \\
\hline HCLD & - & $19.00 \pm 0.26$ & $27.37 \pm 0.48$ & 157.86 & - \\
\hline \multirow{3}{*}{ HCLD/EtSF-S/P } & 1 & $18.88 \pm 0.24$ & $29.04 \pm 0.92$ & 167.58 & 1.68 \\
\hline & 3 & $19.14 \pm 0.30$ & $28.17 \pm 0.47$ & 172.16 & 5.17 \\
\hline & 9 & $18.90 \pm 0.30$ & $27.47 \pm 0.42$ & 166.41 & 14.98 \\
\hline
\end{tabular}

Experimental details were described in Table 1 . The dosages $(\mathrm{g} / \mathrm{kg} /$ day $)$ based on crude herbal material were determined with the amount of ingested diet (g/kg/day) and drug concentrations in the diet. Values given are the means $\pm \mathrm{SEM}$, with $n=10 .{ }^{*} P<0.05$ versus mice fed with ND; ${ }^{\dagger \dagger} P<0.01$ versus mice fed with HCLD. Statistical significant differences were determined using a one-way ANOVA followed by Dunnett's multiple comparisons test or post hoc analysis.

as well as decreased HDL/LDL ratio. These findings suggest that EtSF-P and EtSF-S/P (but not EtSF-S) supplementation may lead to further worsening of lipid parameters in mice under HCL condition. However, it has been reported that the baseline levels of plasma TC, HDL, LDL, and TG in mice were marginally higher than the reference ranges prior to the experiment and 2 weeks of EtSF supplementation did not cause any significant changes in lipid parameters [36].

It is well established that lipid metabolism is closely related to GLU metabolism in the body. The relevant metabolic disorders constitute the pathological basis of hyperlipidemia, metabolic syndrome, type 2 diabetes, fatty liver disease, and obesity [37]. In the present study, supplementation with EtSF-S, EtSF-P, or EtSF-S/P did not change serum TC and TG levels but altered hepatic lipid contents and GLU levels in HCL mice. While EtSF-P and EtSF-S/P supplementation increased hepatic TC contents in HCLD-fed mice, EtSF-S lowered the hepatic TC content. Serum levels of HDL and LDL (often referred to as "good" cholesterol and "bad" cholesterol, resp.) [38] were increased in mice fed with HCLD or ND supplemented with EtSF-P or EtSF-S/P. The elevation of serum HDL and LDL levels by EtSF extracts, in particular the EtSF-S/P, might result from a metabolic response to hypercholesterolemia, wherein the increased cholesterol content necessitates higher levels of LDL and HDL for transportation in the blood. Supplementation with EtSF was found to markedly decrease hepatic TC, TG, and GLU contents in both ND- and HCLD-fed mice. EtSF-S/P supplementation at $1 \%$ increased biliary TC level; however, the supplementation at $9 \%$ reduced biliary TC level and 
increased fecal TC excretion. While EtSF-S attenuated serum TG levels, both EtSF-P and EtSF-S/P did not cause any changes in normal and HCL mice. Taken together, the results suggest that SF can influence the lipid and GLU metabolism in mice in a complex manner, especially under the HCL condition.

A previous study in our laboratory has shown that Sch B lowered fat accumulation in L-02 cells incubated with free fat acid via inhibition of adipose differentiation-related protein (ADRP) and sterol regulatory element-binding protein (SREBP-1) expression [39]. It is known that ADRP is closely associated with intracellular lipid droplets and upregulated in hepatic steatosis [40]. SREBP-1 is the most important transcription factor regulating de novo lipogenesis in the liver and induces insulin resistance [41]. Kwon et al. [42] reported that SF lignans could improve insulin sensitivity via the PPAR- $\gamma$ pathways. Therefore, it is possible that the EtSF extracts tested in the present study may protect against NAFLD and decrease hepatic GLU contents through a similar action mechanism. Hyperlipidemia is commonly associated with insulin resistance, which may result in hyperinsulinemia and hyperglycemia. However, in present study, feeding mice with HCLD did not increase serum GLU levels (data not shown). Instead, HCLD elevated hepatic GLU, which may be related to the stimulation of hepatic gluconeogenesis, an indicative of insulin resistance in extrahepatic tissues. In addition, based on the reduction of hepatic TC content and elevation of serum TC/LDL levels by EtSF extracts in HCLDfed mice, it is possible that EtSF extracts, particularly the EtSF-S/P, can stimulate the release of TC from the liver and thereby ameliorate hepatic steatosis.

The observations of increased serum ALT activity, enlarged liver size, and increased lipid accumulation in the HCLD-fed mice suggest the presence of liver damage, which may result from the accumulation of lipids in hepatic tissue [43] and/or activation of signaling pathways in hepatocytes that stimulate the production of proinflammatory mediators [44]. Supplementation with EtSF-P and EtSF-S/P protected against liver damage in HCL mice, as evidenced by the decrease in serum ALT activity. It is believed that the dibenzocyclooctadiene-type lignans such as schisandrin A and Sch B are the active components of SF in protecting against liver injury [45]. As to why the lignan-enriched EtSF-S was unable to protect against liver damage in HCLD-fed mice remains to be investigated,

FF, the fibrates class of lipid-lowering drugs, is commonly used in the treatment of HLD as a PPAR $\alpha$ agonist for reducing cardiovascular risks and treating NAFLD/nonalcoholic steatohepatitis $[46,47]$, as well as improving the GLU tolerance and lowering adiposity [48]. Significant lowering of serum and hepatic lipid/GLU levels, as well as body weight and fat mass, was observed following FF supplementation (data not shown). As about one-fourth to one-third of blood cholesterol is carried by HDL, hence, low serum HDL levels caused by FF might result from the drug-induced hypocholesterolemia in normal mice. Although fibrate treatment improved liver function in patients with metabolic syndrome in clinic situation [49] and ameliorated concanavalin Ainduced hepatitis in rats [50], FF can cause acute cholestatic hepatitis in patients [51-53]. In the present study, the daily supplementation with FF (130-150 mg/kg; about 30-fold higher than the human dose) induced hepatomegaly and increased ALT levels in normal and HCL mice. FF-induced elevation in serum ALT activity might be partly due to the increased expression of hepatic transaminase gene [54].

Herbal drugs, which contain a mixture of chemical components, can produce a wide spectrum of biological actions. According to the theory of Chinese medicine, SF possesses five tastes (Wu Wei in Chinese)-sweet (fruit skin), sour (pulp), bitter/pungent (seed core), and saltiness (all parts). SF pulp, which mainly contains polysaccharides/sugars and organic acids $[55,56]$ as well as dibenzocyclooctadiene lignans such as schisandrin A, B, and C and gomisin A and $\mathrm{N}$, is responsible for producing most of the pharmacological activities. Although lignans are most abundantly found in SF seeds [57], EtSF-S is not the most biologically active among the 3 tested SF fractions, as observed in the present study. In addition, the pharmacological actions produced by EtSF do not always display a dose-response relationship. For instance, EtSF-S/P reduced hepatic GLU level in a dose-dependent manner, but it did not lower hepatic TC at the highest tested dose (i.e., 9\%). While three doses (1,3, and 9\%) were tested in HCL mice, two doses were adopted in normal mice to examine the possible toxicity of EtSF in mice. Although the daily doses of $9 \%$ EtSF could reach about $15 \mathrm{~g} / \mathrm{kg} / \mathrm{day}$ for 10 days, they did not affect the behaviors in mice (data not shown).

In conclusion, results obtained from the present study showed that the supplementation with EtSF produced a significant influence on lipid/GLU metabolism in ND- and HCLD-fed mice, especially in HCL mice. Dietary supplementation with EtSF-P or EtSF-S/P elevated serum lipid levels, except for that of serum TG levels which was lowered, in HCL mice. Dietary supplementation with EtSF-S, EtSF-P, or EtSF$\mathrm{S} / \mathrm{P}$ reduced hepatic lipid and GLU concentrations in both normal and HCL mice. EtSF-S/P, but not EtSF-S and EtSF$\mathrm{P}$, supplementation increased fecal cholesterol excretion in HCLD-fed mice. EtSF-P and EtSF-S/P attenuated the HCLDinduced hepatotoxicity. Supplementation with FF decreased serum and hepatic lipid and GLU levels, as well as increased serum ALT activity and liver weight in mice fed with ND and/or HCLD (see the summary of results in Table 3). The ensemble of results indicates a differential effect between SF seed and pulp on lipid and GLU metabolism, particularly in HCL mice. Supplementation with EtSF might ameliorate the lipid accumulation in liver cells and thus protect against liver injury in HCL mice.

\section{Conflict of Interests}

The authors declare that there is no conflict of interests with respect to the authorship and/or publication of this paper.

\section{Authors' Contribution}

Xiao-Yan Wang and Zhi-Ling Yu contributed equally to the work. 
TABLE 3: A summary of results from the study.

\begin{tabular}{|c|c|c|c|c|}
\hline & $\begin{array}{c}\text { EtSF-S dietary } \\
\text { supplement }\end{array}$ & $\begin{array}{l}\text { EtSF-P dietary } \\
\text { supplement }\end{array}$ & $\begin{array}{l}\text { EtSF-S/P dietary } \\
\text { supplement }\end{array}$ & $\begin{array}{c}\text { FF } \\
\text { dietary supplement }\end{array}$ \\
\hline \multicolumn{5}{|l|}{ ND-fed mice } \\
\hline Serum TC & - & - & - & $\downarrow$ \\
\hline TG & - & - & - & $\downarrow$ \\
\hline HDL & - & - & - & $\downarrow$ \\
\hline LDL & - & $\uparrow$ & $\uparrow$ & - \\
\hline ALT activity & - & - & - & $\uparrow$ \\
\hline Hepatic TC & $\downarrow$ & - & $\downarrow$ & $\downarrow$ \\
\hline TG & $\downarrow$ & $\downarrow$ & $\downarrow$ & $\downarrow$ \\
\hline Glucose & $\downarrow$ & $\downarrow$ & $\downarrow$ & $\downarrow$ \\
\hline Index & - & - & $\uparrow$ & $\uparrow$ \\
\hline Biliary TC & - & - & - & $\downarrow$ \\
\hline Fecal TC & - & $\uparrow$ & - & - \\
\hline Body weight gain & - & $\downarrow$ & - & $\downarrow$ \\
\hline \multicolumn{5}{|l|}{$\begin{array}{l}\text { HCLD-fed mice } \\
\text { (change versus ND-fed mice) }\end{array}$} \\
\hline Serum TC $(\uparrow)$ & - & $\uparrow$ & $\uparrow$ & $\downarrow$ \\
\hline $\mathrm{TG}(\downarrow)$ & $\downarrow$ & $\downarrow$ & $\downarrow$ & $\downarrow$ \\
\hline HDL (一) & - & $\uparrow$ & $\uparrow$ & - \\
\hline LDL $(\uparrow)$ & - & $\uparrow$ & $\uparrow$ & $\downarrow$ \\
\hline ALT activity $(\uparrow)$ & - & $\downarrow$ & $\downarrow$ & $\uparrow$ \\
\hline Hepatic TC $(\uparrow)$ & $\downarrow$ & $\downarrow$ & $\downarrow$ & $\downarrow$ \\
\hline TG $(\uparrow)$ & $\downarrow$ & $\downarrow$ & $\downarrow$ & $\downarrow$ \\
\hline Glucose $(\uparrow)$ & $\downarrow$ & $\downarrow$ & $\downarrow$ & $\downarrow$ \\
\hline Index $(\uparrow)$ & - & - & - & $\uparrow$ \\
\hline Biliary TC $(\uparrow)$ & $\uparrow$ & - & $\uparrow(1 \%) \downarrow(9 \%)$ & $\uparrow$ \\
\hline Fecal TC $(\uparrow)$ & - & - & $\uparrow$ & - \\
\hline Body weight gain $(-)$ & - & - & - & $\downarrow$ \\
\hline
\end{tabular}

$\uparrow$ : increased or elevated; $\downarrow$ : decreased or inhibited; - : unaltered.

TC: total cholesterol; TG: triglyceride; HDL: high-density lipoprotein; LDL: low-density lipoprotein; ALT: alanine aminotransferase; FF: fenofibrate.

\section{Acknowledgments}

This paper was supported by the National Natural Science Foundation of China (Grant no. 31071989) and the Outstanding Teaching Team of Chinese Herbal Pharmacology in Beijing City (Grant no. 201006).

\section{References}

[1] R. H. Nelson, "Hyperlipidemia as a risk factor for cardiovascular disease," Primary Care, vol. 40, no. 1, pp. 195-211, 2013.

[2] E. van Craeyveld, S. C. Gordts, F. Jacobs, and B. de Geest, "Correlation of atherosclerosis between different topographic sites is highly dependent on the type of hyperlipidemia," Heart and Vessels, vol. 27, no. 2, pp. 231-234, 2012.

[3] P. Loria, G. Marchesini, F. Nascimbeni et al., "Cardiovascular risk, lipidemic phenotype and steatosis. A comparative analysis of cirrhotic and non-cirrhotic liver disease due to varying etiology," Atherosclerosis, vol. 232, no. 1, pp. 99-109, 2014.
[4] B. C. Ip and X. D. Wang, "Non-alcoholic steatohepatitis and hepatocellular carcinoma: implications for lycopene intervention," Nutrients, vol. 6, no. 1, pp. 124-162, 2013.

[5] X. F. Lin, K. Q. Shi, J. You et al., "Increased risk of colorectal malignant neoplasm in patients with nonalcoholic fatty liver disease: a large study," Molecular Biology Reports, 2014.

[6] K. C. Sung, S. H. Wild, and C. D. Byrne, "Development of new fatty liver, or resolution of existing fatty liver, over five years of follow up, and risk of incident hypertension," Journal of Hepatology, 2014.

[7] H. C. Masuoka and N. Chalasani, "Nonalcoholic fatty liver disease: an emerging threat to obese and diabetic individuals," Annals of the New York Academy of Sciences, vol. 1281, pp. 106122, 2013.

[8] C. R. Tian, L. Qian, C. L. Du, and X. Z. Shen, "Increased catabolism of nucleic acid in nonalcoholic fatty liver disease patients of different ages," International Journal of Biological Macromolecules, vol. 65, pp. 107-109, 2014.

[9] A. Eguchi, D. Povero, N. Alkhouri, and A. E. Feldstein, "Novel therapeutic targets for nonalcoholic fatty liver disease," Expert Opinion on Therapeutic Targets, vol. 17, no. 7, pp. 773-779, 2013. 
[10] S. L. di Stasi, T. D. MacLeod, J. D. Winters, and S. A. BinderMacleod, "Effects of statins on skeletal muscle: a perspective for physical therapists," Physical Therapy, vol. 90, no. 10, pp. 1530$1542,2010$.

[11] J. C. Pettersen, I. Pruimboom-Brees, O. L. Francone et al., "The PPAR $\alpha$ agonists fenofibrate and CP-778875 cause increased $\beta$ oxidation, leading to oxidative injury in skeletal and cardiac muscle in the rat," Toxicologic Pathology, vol. 40, no. 3, pp. 435447, 2012.

[12] H. Buyukhatipoglu, Y. Sezen, U. Guntekin, I. Kirhan, and O. F. Dag, "Acute renal failure with the combined use of rosuvastatin and fenofibrate," Renal Failure, vol. 32, no. 5, pp. 633-635, 2010.

[13] V. M. Alla, V. Agrawal, A. DeNazareth, S. Mohiuddin, S. Ravilla, and M. Rendell, "A reappraisal of the risks and benefits of treating to target with cholesterol lowering drugs," Drugs, vol. 73, no. 10, pp. 1025-1054, 2013.

[14] V. Carreau, J.-P. Girardet, and E. Bruckert, "Long-term followup of statin treatment in a cohort of children with familial hypercholesterolemia: efficacy and tolerability," Pediatric Drugs, vol. 13, no. 4, pp. 267-275, 2011.

[15] Z. L. Liu, G. Q. Li, A. Bensoussan, H. Kiat, K. Chan, and J. P. Liu, "Chinese herbal medicines for hypertriglyceridaemia," The Cochrane Database of Systematic Reviews, vol. 6, Article ID CD009560, 2013.

[16] B. Wider, M. H. Pittler, J. Thompson-Coon, and E. Ernst, "Artichoke leaf extract for treating hypercholesterolaemia," The Cochrane Database of Systematic Reviews, no. 4, Article ID CD003335, 2013.

[17] Y. Takimoto, H. Y. Qian, E. Yoshigai, T. Okumura, Y. Ikeya, and M. Nishizawa, "Gomisin N in the herbal drug gomishi (Schisandra chinensis) suppresses inducible nitric oxide synthase gene via C/EBP $\beta$ and NF- $\kappa \mathrm{B}$ in rat hepatocytes," Nitric Oxide, vol. 28, pp. 47-56, 2013.

[18] Y. Xu, Z. Liu, J. Sun et al., "Schisandrin B prevents doxorubicininduced chronic cardiotoxicity and enhances its anticancer activity in vivo," PLoS ONE, vol. 6, no. 12, Article ID e28335, 2011.

[19] H. Bi, F. Li, K. W. Krausz, A. Qu, C. H. Johnson, and F. J. Gonzalez, "Targeted metabolomics of serum acylcarnitines evaluates hepatoprotective effect of wuzhi tablet (schisandra sphenanthera extract) against acute acetaminophen toxicity," Evidence-Based Complementary and Alternative Medicine, vol. 2013, Article ID 985257, 13 pages, 2013.

[20] A. Panossian and G. Wikman, "Pharmacology of Schisandra chinensis Bail.: an overview of Russian research and uses in medicine," Journal of Ethnopharmacology, vol. 118, no. 2, pp. 183-212, 2008.

[21] H. J. Park, S. J. Lee, Y. Song et al., "Schisandra chinensis prevents alcohol-induced fatty liver disease in rats," Journal of Medicinal Food, vol. 17, no. 1, pp. 103-110, 2014.

[22] N. Tatewaki, H. Nishida, M. Yoshida et al., "Differential effect of schisandrin B stereoisomers on ATR-mediated DNA damage checkpoint signaling," Journal of Pharmacological Sciences, vol. 122, no. 2, pp. 138-148, 2013.

[23] S.-Y. Pan, Z.-L. Yu, H. Dong, C.-J. Xiang, W.-F. Fong, and K.-M. Ko, "Ethanol extract of fructus schisandrae decreases hepatic triglyceride level in mice fed with a high fat/cholesterol diet, with attention to acute toxicity," Evidence-based Complementary and Alternative Medicine, vol. 2011, Article ID 729412, 6 pages, 2011.

[24] S. Y. Pan, Q. Yu, Y. Zhang et al., "Dietary Fructus Schisandrae extracts and fenofibrate regulate the serum/hepatic lipid-profile in normal and hypercholesterolemic mice, with attention to hepatotoxicity," Lipids in Health and Disease, vol. 11, p. 120, 2012.

[25] S.-Y. Pan, H. Dong, X.-Y. Zhao et al., "Schisandrin B from Schisandra chinensis reduces hepatic lipid contents in hypercholesterolaemic mice," The Journal of Pharmacy and Pharmacology, vol. 60, no. 3, pp. 399-403, 2008.

[26] S.-Y. Pan, H. Dong, Z.-L. Yu et al., "Bicyclol, a synthetic dibenzocyclooctadiene derivative, decreases hepatic lipids but increases serum triglyceride level in normal and hypercholesterolaemic mice," The Journal of Pharmacy and Pharmacology, vol. 59, no. 12, pp. 1657-1662, 2007.

[27] S.-Y. Pan, R. Yang, H. Dong, Z.-L. Yu, and K.-M. Ko, "Bifendate treatment attenuates hepatic steatosis in cholesterol/bile salt- and high-fat diet-induced hypercholesterolemia in mice," European Journal of Pharmacology, vol. 552, no. 1-3, pp. 170-175, 2006.

[28] X. R. Yang, E. Wat, Y. P. Wang et al., "Effect of dietary cocoa tea (Camellia ptilophylla) supplementation on high-fat dietinduced obesity, hepatic steatosis, and hyperlipidemia in mice," Evidence-Based Complementary and Alternative Medicine, vol. 2013, Article ID 783860, 11 pages, 2013.

[29] M. Gu, S. Fan, G. Liu et al., "Extract of wax gourd peel prevents high-fat diet-induced hyperlipidemia in C57BL/6 mice via the inhibition of the PPAR $\gamma$ pathway," Evidence-Based Complementary and Alternative Medicine, vol. 2013, Article ID 342561, 11 pages, 2013.

[30] S. Zelber-Sagi, F. Salomone, H. Yeshua et al., "Non-high-density lipoprotein cholesterol independently predicts new onset of non-alcoholic fatty liver disease," Liver International, 2013.

[31] M. L. Fernandez and D. Webb, "The LDL to HDL cholesterol ratio as a valuable tool to evaluate coronary heart disease risk," Journal of the American College of Nutrition, vol. 27, no. 1, pp. $1-5,2008$.

[32] H. Liang, X. Chen, Q. Chen et al., "The metabolic syndrome among postmenopausal women in rural Canton: prevalence, associated factors, and the optimal obesity and atherogenic indices," PLoS ONE, vol. 8, no. 9, Article ID e74121, 2013.

[33] M. Landén, F. Baghaei, R. Rosmond, G. Holm, P. Björntorp, and E. Eriksson, "Dyslipidemia and high waist-hip ratio in women with self-reported social anxiety," Psychoneuroendocrinology, vol. 29, no. 8, pp. 1037-1046, 2004.

[34] S. Baligadoo, "Elevated coronary mortality in Mauritius: risk factors and genetic analyses," Bulletin de L’Académie NationaLe de Médecine, vol. 196, no. 7, pp. 1381-1394, 2012.

[35] L. Masana, D. Ibarretxe, M. Heras et al., "Substituting nonHDL cholesterol with LDL as a guide for lipid-lowering therapy increases the number of patients with indication for therapy," Atherosclerosis, vol. 226, no. 2, pp. 471-475, 2013.

[36] D. Tsi and A. Tan, "Evaluation on the combined effect of Sesamin and Schisandra extract on blood fluidity," Bioinformation, vol. 2, no. 6, pp. 249-252, 2008.

[37] E. Iori, B. Vinci, E. Murphy, M. C. Marescotti, A. Avogaro, and A. Ahluwalia, "Glucose and fatty acid metabolism in a 3 tissue in-vitro model challenged with normo- and hyperglycaemia," PLoS ONE, vol. 7, no. 4, Article ID e34704, 2012.

[38] N. A. Elshourbagy, H. V. Meyers, and S. S. Abdel-Meguid, "Cholesterol: the good, the bad, and the ugly-therapeutic targets for the treatment of dyslipidemia," Medical Principles and Practice, vol. 23, no. 2, pp. 99-111, 2014.

[39] J.-H. Chu, H. Wang, Y. Ye et al., "Inhibitory effect of schisandrin $\mathrm{B}$ on free fatty acid-induced steatosis in L-02 cells," World Journal of Gastroenterology, vol. 17, no. 19, pp. 2379-2388, 2011. 
[40] T. Okumura, "Role of lipid droplet proteins in liver steatosis," Journal of Physiology and Biochemistry, vol. 67, no. 4, pp. 629636, 2011.

[41] D. Müller-Wieland, B. Knebel, J. Haas, and J. Kotzka, "SREBP1 and fatty liver-clinical relevance for diabetes, obesity, dyslipidemia and atherosclerosis," Herz, vol. 37, no. 3, pp. 273-278, 2012.

[42] D. Y. Kwon, D. S. Kim, H. J. Yang, and S. Park, "The lignan-rich fractions of Fructus Schisandrae improve insulin sensitivity via the PPAR- $\gamma$ pathways in in vitro and in vivo studies," Journal of Ethnopharmacology, vol. 135, no. 2, pp. 455-462, 2011.

[43] B. Joseph, S. Kapoor, M. L. Schilsky, and S. Gupta, "Bile saltinduced pro-oxidant liver damage promotes transplanted cell proliferation for correcting Wilson disease in the Long-Evans Cinnamon rat model," Hepatology, vol. 49, no. 5, pp. 1616-1624, 2009.

[44] K. Allen, H. Jaeschke, and B. L. Copple, "Bile acids induce inflammatory genes in hepatocytes: a novel mechanism of inflammation during obstructive cholestasis," American Journal of Pathology, vol. 178, no. 1, pp. 175-186, 2011.

[45] F. Yan, Q.-Y. Zhang, L. Jiao et al., "Synergistic hepatoprotective effect of Schisandrae lignans with Astragalus polysaccharides on chronic liver injury in rats," Phytomedicine, vol. 16, no. 9, pp. 805-813, 2009.

[46] A. Sahebkar, G. T. Chew, and G. F. Watts, "New peroxisome proliferator-activated receptor agonists: potential treatments for atherogenic dyslipidemia and non-alcoholic fatty liverdisease," Expert Opinion on Pharmacotherapy, vol. 15, no. 4, pp. 493-503, 2014.

[47] M. S. Kostapanos, A. Kei, and M. S. Elisaf, "Current role of fenofibrate in the prevention and management of non-alcoholic fatty liver disease," World Journal of Hepatology, vol. 5, no. 9, pp. 470-478, 2013.

[48] A. V. Ferreira, Z. Menezes-Garcia, E. G. Mario, H. L. Delpuerto, A. S. Martins, and L. M. Botion, "Increased expression of oxidative enzymes in adipose tissue following PPARa-activation," Metabolism, vol. 63, no. 4, pp. 456-460, 2014.

[49] N. Gandhi, R. Lenton, M. Bhartia, A. Abbas, J. Raju, and S. Ramachandran, "Effect of fibrate treatment on liver function tests in patients with the metabolic syndrome," Springerplus, vol. 3, p. 14, 2014.

[50] D. I. Mohamed, A. A. Elmelegy, L. F. El-Aziz, H. S. Abdel Kawy, A. A. El-Samad, and O. A. El-Kharashi, "Fenofibrate A peroxisome proliferator activated receptor- $\alpha$ agonist treatment ameliorates Concanavalin A-induced hepatitis in rats," European Journal of Pharmacology, vol. 721, no. 1-3, pp. 35-42, 2013.

[51] D. Hajdu, K. Aiglová, I. Vinklerová, and K. Urbánek, "Acute cholestatic hepatitis induced by fenofibrate," Journal of Clinical Pharmacy and Therapeutics, vol. 34, no. 5, pp. 599-602, 2009.

[52] N. Tudesq and M. Bentounes, "Hepatitis induced by fibrates," Annales de Biologie Clinique, vol. 64, no. 5, pp. 515-516, 2006.

[53] B. Maroy, "Acute cholestatic hepatitis probably due to fenofibrate," Therapie, vol. 65, no. 2, pp. 147-148, 2010.

[54] A. Kobayashi, Y. Suzuki, H. Kuno, S. Sugai, H. Sakakibara, and K. Shimoi, "Effects of fenofibrate on plasma and hepatic transaminase activities and hepatic transaminase gene expression in rats," Journal of Toxicological Sciences, vol. 34, no. 4, pp. 377-387, 2009.

[55] L. S. Li, W. J. Shi, and X. B. Ma, "Comparative analysis of bioactive component in seeds and flesh of Schisandrae chinensis Fructus by thin layer chromatography," Food Science, vol. 33, no. 16, pp. 175-178, 2012.
[56] L. Li, Y. Xiao, D. Yu et al., "Determination of three organic acids in Schisandrae Chinensis Fructus by HPLC," China Journal of Chinese Materia Medica, vol. 36, no. 23, pp. 3286-3289, 2011.

[57] C. Schwarzinger and H. Kranawetter, "Analysis of the active compounds in different parts of the Schisandra chinensis plant by means of pyrolysis-GC/MS," Monatshefte fur Chemie, vol. 135, no. 9, pp. 1201-1208, 2004. 


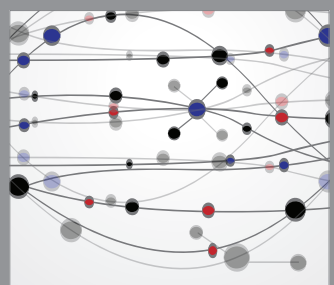

The Scientific World Journal
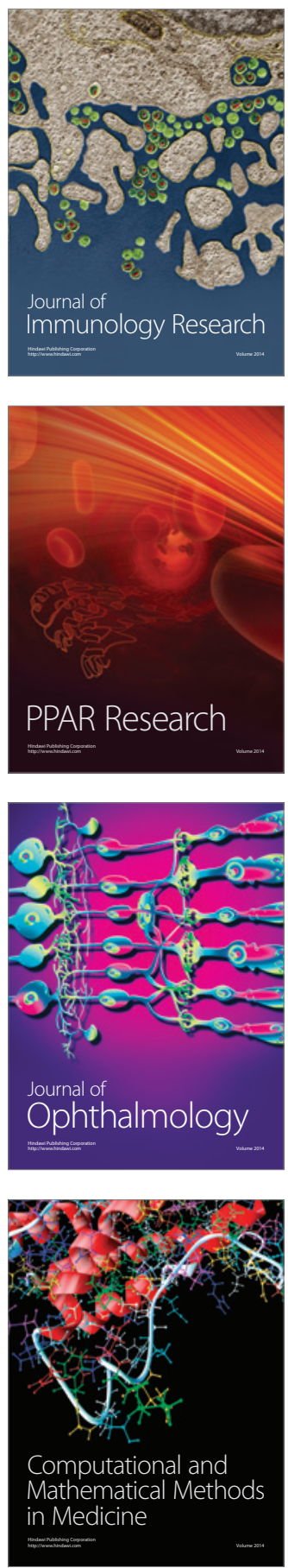

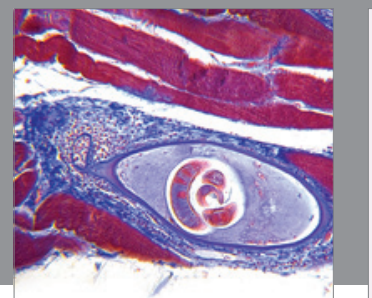

Gastroenterology

Research and Practice
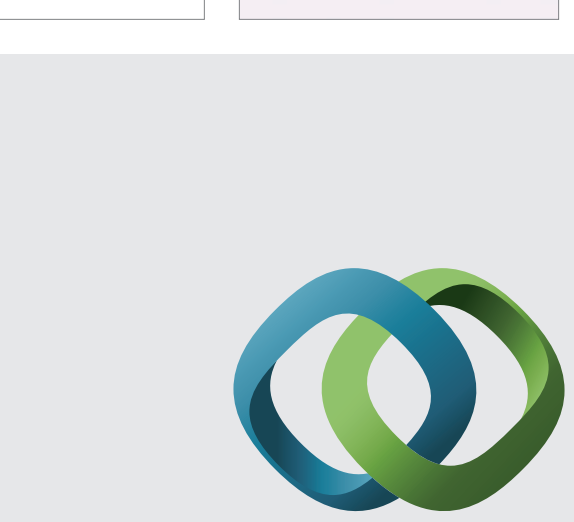

\section{Hindawi}

Submit your manuscripts at

http://www.hindawi.com
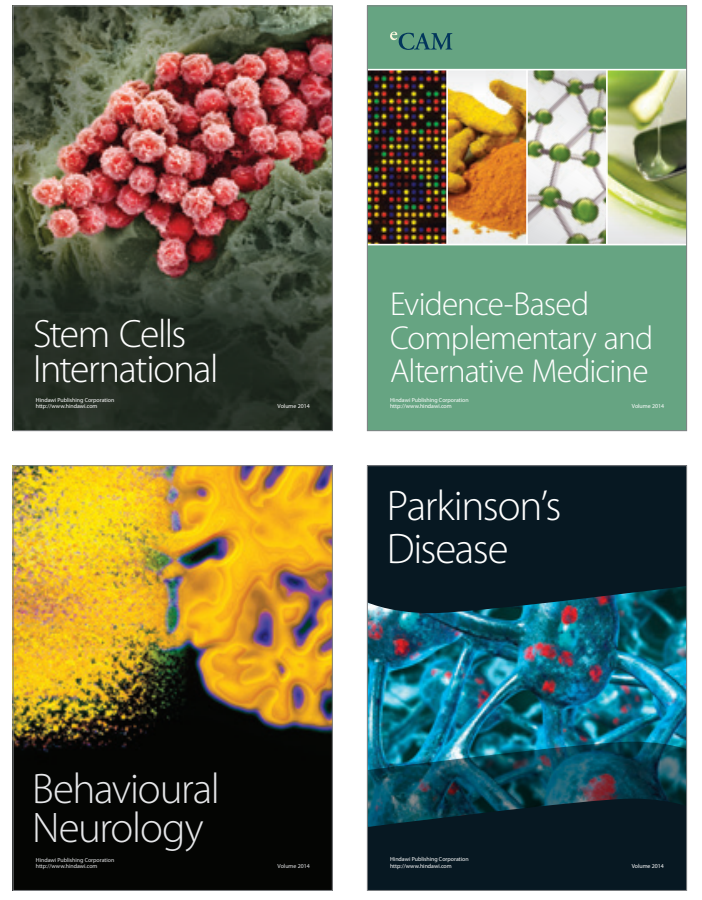
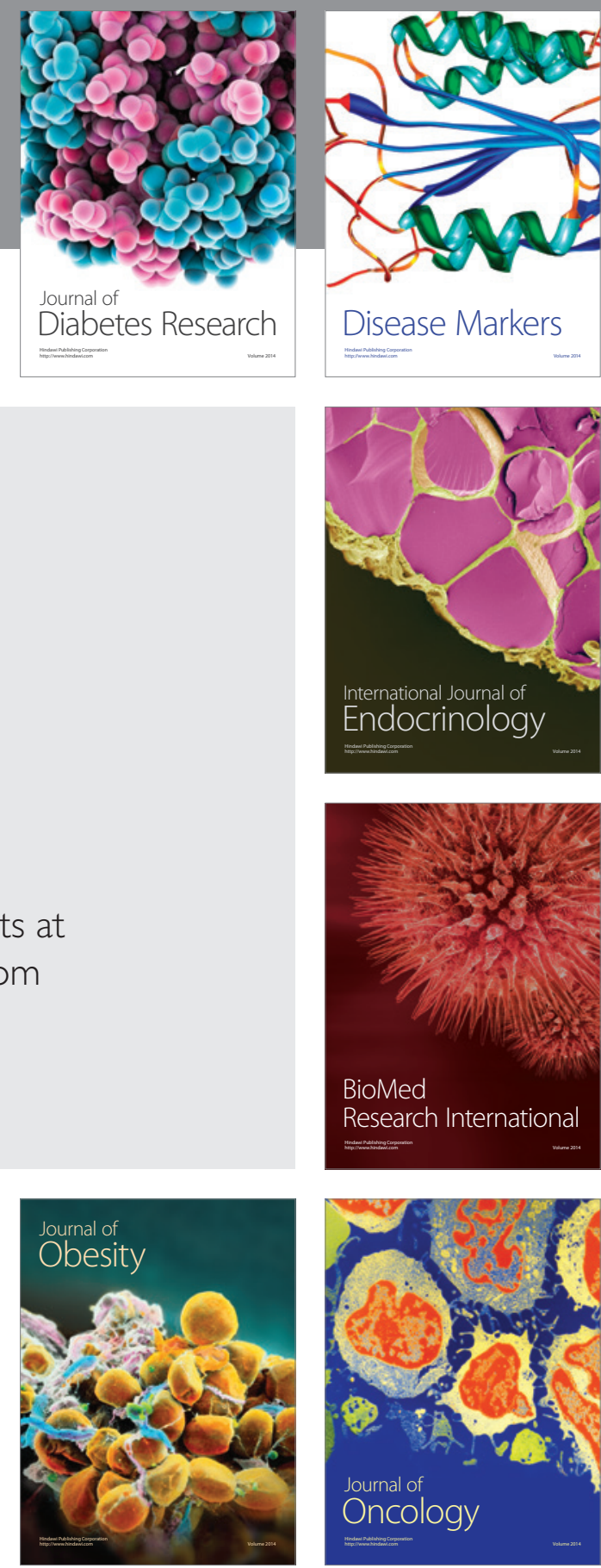

Disease Markers
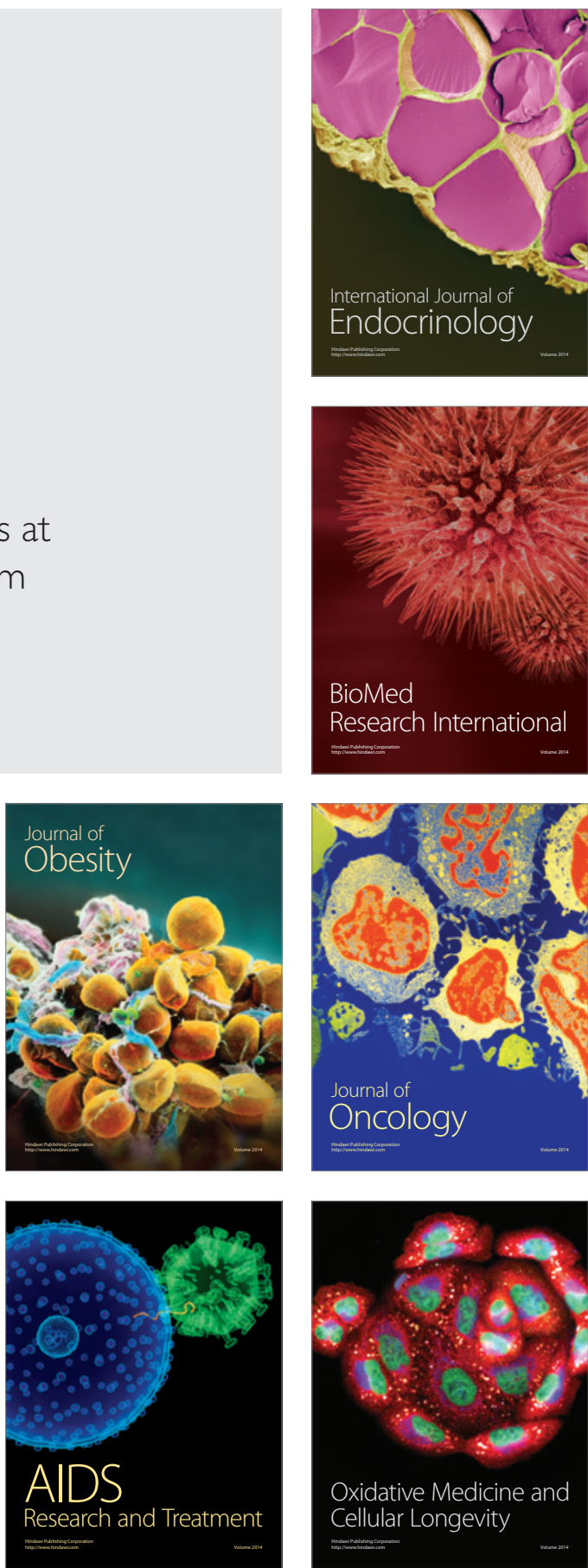